MedieKultur | Journal of media and communication research | ISSN 1901-9726

Book Review

\title{
James Curran, Natalie Fenton \& Des Freedman: Misunderstanding the Internet. London, New York: Routledge. 2012.
}

\section{Christina Neumayer}

MedieKultur 2013, 55, 113-115

Published by SMID | Society of Media researchers In Denmark | www.smid.dk The online version of this text can be found open access at www.mediekultur.dk

A colleague entered my office and saw Misunderstanding the Internet, the book I am reviewing, lying on my desk. His comment was: "Everything, we thought, would change with the internet and all the positive things we expected to happen - after reading this, I know it's all wrong." Misunderstanding the Internet indeed goes beyond techno-optimistic visions about the internet and uncovers myths about revolutionary changes in the digital age. The authors reveal the mismatch between the utopian ideas and the social, legal and economic concept the internet is based upon. James Curran, Natalie Fenton and Des Freedman present a critical perspective, based on a political economy of communication approach rooted in a Marxist tradition, to debunk the idea of the transformative power of the internet over society. By understanding these misconceptions, the book attempts to reinterpret the internet. From historical, legal, economic and political perspectives, the authors convincingly uncover many of the internet's myths. The book is divided into three parts, each of them written by one of the authors. At the end of the book the three authors together draw conclusions based on their findings.

In the opening chapters, James Curran creates a counter-argument to the prophecy of technology, "a belief that the internet is the alpha and omega of technologies, an agency that overrides all obstacles" (p. 3). He provides an overview of the various optimistic ideas about the internet as a technology of empowerment, democracy, economic growth and communication across national boundaries. Despite all the myths created around the internet's empowering potential, Curran elegantly argues, the corporate "Goliaths contin- 
ued to squash commercial Davids armed only with a virtual sling and pebble" (p. 7). The internet has invigorated activism, as a positive contribution to democracy, as well as supported manipulation and centralisation in the political environment, depending on the different political contexts. Actual change will consequently mainly "come from society, not the microchip" (p. 12). Curran uses examples from Arab countries, China and India for "de-Westernising internet history" (p. 35) and concludes by arguing for a de-capitalisation of the "Internet" to emphasise that society exerts a greater influence on the internet than the internet on society. The "Newspaper Press" in the $19^{\text {th }}$ century was accompanied with a similar libertarian, fetishising and hyperbolic discourse and later turned into the "newspaper press". The urge to understand the larger societal context of the internet and to move away from too optimistic, techno-deterministic perspectives has been expressed by a number of other authors (see, for example, Cammaerts, 2008; Morozov, 2011; Turner, 2006). James Curran's chapters in this book provide an excellently written contribution to this body of literature.

In the second part, Des Freedman continues the adventure of correcting overhyped misunderstandings of the internet as transformative power. Using the neo-Marxist arguments of alienation and exploitation by unpaid labour, commodification and concentration in the digital media economy, Freedman creates a counter-argument to the prosperous "New Economy" induced by web technology. The economic revolution brought about by the ideal of an inherently democratic technology combined with venture capitalism would "put an end to the rule of monopolies and inspire more decentralised and customised networks of media flows" (p. 69). On the contrary, Des Freedman shows with a fact-driven argument that "digital capitalism is still subject to the same episodic crises of supply and demand and the same periods of speculation that affect other varieties of capitalism" ( $p$. 92). Fetishising openness cannot cover up proprietary behaviour and hence, processes of monopolisation, commodification and accumulation of the digital media economy, which were the same problems that the mass media economy faced. The regulation that fosters these developments is increasingly non-governmentalised, with the argument of the global reach of internet technology. At the same time, national regulations are still powerful. The internet is neither free nor open nor a magical object, but "a built environment based on the visions and actions of a range of architects" (p. 116). With this chapter, Des Freedman lays the groundwork for the conclusion of Misunderstanding the Internet: We need "a commitment to forms of regulation that are not subservient to corporate pressure, government priorities or elite control" but regulation "to fend off the distortion of the public good by special interests" (p. 117).

In the third part, entitled "Internet and Power", Natalie Fenton contrasts utopian ideas about the role of social media in civic engagement and empowerment with a less revolutionary reality. Social networking sites, she argues, rather than conferring agency "reinforce already existing social hierarchies and further strengthen close(d) communities" ( $p$. 127). The mistakenly hyperbolic ideas of empowerment of radical politics and resistance in 
the digital age can dilute the possibility for real empowerment, support existing corporate power and inequalities, and be counterproductive to resistance. Under the right conditions, the loosely connected radical groups across different subject positions can incite counter-political movements, but "too frequently people overestimate the capacity of resistive potential to rise up" (p. 170). Fenton takes the revisionism of perspectives of Misunderstanding the Internet into the radical political realm. "Genuine democratisation requires the real and material participation" and "should not give way to a fetishisation of autonomy through notions of participation or interactivity" (p. 142). Fenton stresses the expressive dimension of the social web that can provide a space for articulating rather than bringing about social change, self-expression rather than revolution. The internet with its embedded forms of capitalism needs the right ingredients and conditions to "help bring about a counter-politics and counter-political movements - creating the perfect soufflé" (p. 170). Misunderstanding the quality of ingredients by overrating the potential of the articulation of counter politics, on the contrary, can be counter-productive for radical politics.

In their conclusion, the authors have suggestions for what can be done. Through regulation, the corporate influence on the internet could be decreased. They suggest to "think the unthinkable and contemplate a different way of managing the internet" (p. 180). Public policy, they argue, could lead to a more democratic internet, "an internet that is run for the benefit of the public without discrimination by market or state" (p. 184). This call for regulation sounds convincing to the reader due to the thorough analysis the authors provide. The proposal that the authors very briefly present, however, leaves the reader dissatisfied after the brilliant analysis that precedes the conclusion. As compelling as the introduction of internet taxes, changes in intellectual property rights, and a deliberate public policy are, and as important and urgent (as the authors by their analysis demonstrate) as these needed changes are, it is unfortunately unlikely that society will live up to this challenge.

\title{
References
}

Cammaerts, B. (2008). Critiques on the participatory potentials of Web 2.0. Communication, Culture \& Critique, 1(4), 358-377.

Morozov, E. (2011). The net delusion: How not to liberate the world. New York: Public Affairs.

Turner, F. (2006). From counterculture to cyberculture. Stewart Brand, the whole earth network, and the rise of digital utopianism. Chicago, London: The University of Chicago Press.

\author{
Christina Neumayer \\ Postdoctoral Fellow, PhD \\ Culture, Aesthetic, Organisations \& Society Section \\ IT University of Copenhagen, Denmark \\ chne@itu.dk
}

